\title{
ATLETISMO E ENSINO DA HISTÓRIA E CULTURA AFRO-BRASILEIRA: VISÃO DE PROFESSORES DE EDUCAÇÃO FÍSICA PARTICIPANTES DE UM CURSO DE EXTENSÃO A DISTÂNCIA
}

\author{
ATHLETICS AND TEACHING OF AFRICAN BRAZILIAN HISTORY AND \\ CULTURE: THE VIEW OF PHYSICAL EDUCATION TEACHERS PARTICIPATING \\ IN A COMMUNITY OUTREACH DISTANCE EDUCATION COURSE
}

\section{ATLETISMO Y ENSEÑANZA DE LA HISTORIA Y CULTURA AFROBRASILEÑA: VISIÓN DE PROFESORES DE EDUCACIÓN FISICA PARTICIPANTES DE UN CURSO DE EXTENSIÓN A DISTANCIA}

\section{Eduardo Vinícius Mota e Silva*, Sara Quenzer Matthiesen ${ }^{* *}$}

\section{Palavras chave: Educação Física e Treinamento. Atletismo. \\ Educação a \\ Distância.}

Grupos étnicos.
Resumo: Averiguar a visão de participantes de um curso de extensão a distância sobre a adequação do Atletismo para o ensino da História e Cultura Afro-Brasileira é o objetivo deste artigo. Para a obtenção destas informações optou-se pela realização de uma pesquisa do tipo qualitativa e online. Foram considerados os registros disponibilizados pela Plataforma Moodle, obtidos por meio de um questionário aberto e das livres manifestações nos diversos fóruns disponibilizados. Para o tratamento destes dados utilizou-se a técnica de Análise do Conteúdo. Foram identificadas as seguintes subcategorias: a) adequada ao tratamento da temática; reprodutora da diversidade étnica brasileira; b) espaço de afirmação da cultura negra; c) possibilidade não exclusiva de tratamento e d) enfoque inovador e conteúdo aplicável às aulas de Educação Física. Verificou-se, então, que, na opinião dos participantes, o Atletismo apresenta grande potencialidade para o tratamento da História e Cultura Afro-Brasileira em aulas de Educação Física.
Keywords: Physical Education and Training. Athletics.

Education, Distance. Ethnic Groups.

Abstract: This article looks into the perspective of participants in a community outreach distance education course over the suitability of Athletics for teaching African Brazilian History and Culture through a qualitative online research. It examined records provided on the Moodle Platform and obtained through open questionnaires and spontaneous manifestations on various forums. Data processing used Content Analysis. The following subcategories were identified: a) appropriate approach for addressing the topic; reproducing Brazil's ethnic diversity; b) space for asserting black culture; c) non-exclusive approach; and d) innovative approach and content applicable in Physical Education classes. Based on participants' opinions, Athletics was found to show huge potential for approaching African Brazilian History and Culture in Physical Education classes.

Palabras clave: Educación Física y Entrenamiento. Atletismo.

Educación a

Distancia

Grupos étnicos.
Resumen: Averiguar la visión de participantes de un curso de extensión a distancia sobre la adecuación del Atletismo para la enseñanza de la Historia y Cultura Afrobrasileña es el objetivo de este artículo. Para la obtención de estas informaciones se realizó una investigación cualitativa y online. Se consideraron los registros disponibles en la Plataforma Moodle, obtenidos a través de un cuestionario abierto y de las libres manifestaciones en los diversos foros disponibles. Para el tratamiento de estos datos se utilizó la técnica de Análisis de Contenido. Se identificaron las siguientes subcategorías: a) adecuada para el tratamiento de la temática; reproductora de la diversidad étnica brasileña; b) espacio de afirmación de la cultura negra; c) posibilidad no exclusiva de tratamiento y d) enfoque innovador y contenido aplicable a las clases de Educación Física. Se verificó, entonces, que en opinión de los participantes el Atletismo presenta gran potencialidad para el tratamiento de la Historia y Cultura Afrobrasileña en clases de Educación Física.
*Universidade Federal do Ceará. Fortaleza, CE, Brasil.

E-mail: profeduardomota@ hotmail.com

**Universidade Estadual Paulista "Júlio de Mesquita Filho". Rio Claro, SP, Brasil.

E-mail: saraqm@rc.unesp.br

Recebido em: 02-09-2017 Aprovado em: 24-11-2017

$\mathrm{DOl}:$ http://dx.doi.org/10.22456/1982-8918.75789 (c) (1) (8) Licence 


\section{INTRODUÇÃO}

Com a promulgação das leis nำ10.639/2003 e nำ11.645/2008, que alteraram o artigo 26-A da Lei de Diretrizes e Bases da Educação Nacional (LDB) para inclusão, respectivamente da temática "História e Cultura Afro-Brasileira" e "Indígena", instituiu-se que os diferentes componentes curriculares da Educação Básica deveriam incluir "[...] conteúdos referentes à História e Cultura Afro-Brasileira" em seus currículos (BRASIL, 2008). De acordo com os Parâmetros Curriculares Nacionais, o componente curricular Educação Física é o responsável por tematizar as diferentes manifestações da cultura corporal de movimento: "[...] 0 jogo, a ginástica, o esporte, a dança, a capoeira e outras temáticas que apresentarem relações com os principais problemas dessa cultura corporal de movimento e o contexto histórico-social dos alunos" (BRASIL, 1998, p. 26).

Apesar disso e do tempo já decorrido da elaboração dessas leis, verifica-se que, apesar da produção crescente, ainda há relativamente pouco implantado ou produzido a respeito da inclusão de conteúdos da cultura afro-brasileira na disciplina que tematiza a cultura corporal de movimento: a Educação Física (SOARES, 2015). Podem ser citados, neste sentido, os estudos de Rangel (2006); Rangel et al. (2008); Mattos (2007); Santos (2007); Rodrigues (2013) e Pirez e Souza (2015).

O presente artigo tem entre suas premissas discutir as possibilidades de se fazer esta inclusão naquela que é a mais predominante manifestação da cultura corporal de movimento no período contemporâneo, o esporte (TUBINO, 2010; GALVÃO; RODRIGUES; SANCHES NETO, 2011). Importante lembrar, aliás, que este conteúdo foi ou é praticamente hegemônico nas aulas de Educação Física (BRACHT, 2010), se limita "[...] ao contexto estadunidense e/ou europeu do futebol, voleibol, basquetebol e handebol" (GONÇALVES JUNIOR, 2009, p. 704) e, muitas vezes, se vale de um processo de ensino limitado a um fazer descompromissado, o que oblitera uma grande oportunidade de se discutir as grandes questões sociais que 0 envolvem.

Embora a opção pelo conteúdo Esporte como elemento para o ensino da História e Cultura Afro-Brasileira seja passível de críticas por este ser, a princípio, um fenômeno de origem europeia, é importante ressaltar que, durante seu desenvolvimento, este passou a ter caráter universal, tendo, inclusive, vários filhos da diáspora africana como protagonistas (OLIVEIRA, 2008). Rodrigues e Galvão (2011, p. 90-91) reforçam a possibilidade de sua utilização ao afirmarem que o esporte, por "[...] estar sempre presente na mídia, relevando e revelando conflitos", pode ser gerador de reflexões sobre temas como a prática de discriminação nas atividades esportivas, tema caro à educação das relações étnico-raciais, objeto, também, da promulgação das leis anteriormente mencionadas.

Neste estudo, especificamente, fez-se a opção por estudar este fenômeno via uma das principais modalidades esportivas da Educação Física, o Atletismo, considerado por Matthiesen (2007) um conteúdo clássico da área, inclusive por estar presente desde a primeira edição dos antigos Jogos Olímpicos Gregos, realizada em 776 a. C. Aliás, em relação a essa modalidade, há indícios de que as origens de algumas de suas provas atuais estivessem, inclusive, muito além do mundo grego. Oro (2009, p. 18), com base em informações de especialistas alemães, afirma que dentre estas existem "[...] também exercícios de origem africana". Com base em Vieira e Freitas (2007) depreende-se que o autor faça referência, neste caso, à descoberta feita 
por outros estudiosos, não citados, de que havia provas de arremesso de pedras, precursoras do arremesso do peso, em festividades da civilização egípcia.

Esse exemplo, por si só, demonstra a viabilidade de se tratar das questões afeitas às relações étnico-raciais e a História e Cultura Afro-Brasileira por meio do Atletismo. Mas, além deste fato, sabe-se que houve diversos fatos ou fatores que fizeram com que os povos de origem africana tivessem papel destacado em seu desenvolvimento. Destaque esse que não se limitou apenas à sua predominância nas pistas, por meio de inúmeros títulos e recordes, mas também fora delas, tanto que o último presidente de sua principal entidade, a Associação Internacional das Federações de Atletismo (IAAF), foi um africano, o senegalês Lamine Diak. Tendo em vista estas possibilidades, a constatação de que pouco foi produzido neste sentido e a necessidade de que este tipo de informação fosse disseminado para que se pudesse verificar a real pertinência de sua utilização em aulas de Educação Física, buscou-se, neste estudo, averiguar a visão de participantes de um curso de extensão a distância sobre Atletismo e ensino da História e Cultura Afro-Brasileira, a respeito da adequação desta modalidade à temática.

\section{PROCEDIMENTOS METODOLÓGICOS}

Para a consecução deste objetivo lançou-se mão de uma pesquisa do tipo qualitativa. Para Lüdke e André (1986, p.18) esse método "[...] se desenvolve numa situação natural, é rico em dados descritivos, tem um plano aberto e flexível e focaliza a realidade de forma complexa e contextualizada". Para Cavalcante, Calixto e Pinheiro (2014, p.14), esse tipo de abordagem permite "[...] desvelar processos sociais ainda pouco conhecidos" como a utilização da Educação a Distância (EAD) tanto para a formação continuada de professores, quanto para o ensino da História e Cultura Afro-Brasileira nas aulas de Educação Física, por meio do Atletismo. Como, neste caso, a realidade investigada deu-se no ambiente virtual, uma vez que tanto o curso quanto a coleta de dados ocorreram por meio da internet, foi necessária a adoção de um método adequado a este ambiente, a pesquisa online, possibilidade metodológica da pesquisa qualitativa, que tem como vantagem o acompanhamento quase imediato dos dados obtidos (MENDES, 2009).

Para que se pudesse, então, compreender melhor o fenômeno aqui investigado, fez-se uma pesquisa de campo, justamente para que se conseguissem informações ou conhecimentos necessários para a resolução do problema de pesquisa, conforme entendimento de Marconi e Lakatos (2013). Esta pesquisa, portanto, consistiu na análise da visão dos participantes acerca de um curso de extensão a distância para o ensino da História e Cultura Afro-Brasileira, por meio do Atletismo, em aulas de Educação Física. Detalha-se, na sequência, o curso elaborado para a realização deste estudo.

\subsection{A elaboração do curso}

o curso de extensão intitulado "Introdução ao ensino da História e Cultura Afro-Brasileira em aulas de Educação Física: possibilidades de ensino por meio do Atletismo" teve como público-alvo estudantes e licenciados em Educação Física. Seu principal objetivo foi capacitar professores de Educação Física a: a) compreender os fundamentos e as determinações das 
Leis no 10.639/03 e n 11.645/07; e, b) incluir o ensino da História e Cultura Afro-Brasileira em aulas de Educação Física por meio da utilização dos aspectos históricos da modalidade esportiva Atletismo. Para tal, a carga horária total do curso foi de 30 horas, divididas em cinco semanas de realização. Sua proposta pedagógica se pautou em três princípios. 0 primeiro deles foi a utilização dos fundamentos da aprendizagem colaborativa, fator fundamental para que a interação entre os diferentes atores (cursistas e tutor) realmente acontecesse de modo a garantir a qualidade de um curso a distância (AMARAL, 2011). O segundo princípio consistiu na utilização das ideias do multiculturalismo crítico que pode ser definido como a vertente deste movimento que busca

[...] ir além da valorização da diversidade cultural em termos folclóricos ou exóticos, para questionar a própria construção das diferenças e, por conseguinte, dos estereótipos e preconceitos contra aqueles percebidos como 'diferentes' no seio de sociedades desiguais e excludentes (CANEN; OLIVEIRA, 2002, p. 61).

Já o terceiro princípio consistiu na apresentação de atividades voltadas às aulas de Educação Física na Educação Básica, formulada por Darido et al. (2006), que contemplassem o tratamento dos temas transversais, a partir da leitura de textos baseados na mídia impressa. A grande diferença nesse quesito, na proposta aqui apresentada, está nas possibilidades abertas pela internet de utilizar materiais midiáticos em outros formatos além do impresso.

Este curso foi oferecido na modalidade de extensão universitária, inclusive por ser esta uma das possibilidades apontadas pelas Diretrizes Curriculares Nacionais (DCN) para a Educação das Relações Étnico-Raciais e para o Ensino de História e Cultura Afro-Brasileira e Africana a serem desenvolvidas pelas Instituições de Ensino Superior (BRASIL, 2004) e foi composto por três etapas: 1- Introdução; 2- Desenvolvimento: composto pelas justificativas do curso e três temas relacionados aos conteúdos propostos pelas referidas DCN: História da África e dos Africanos, a cultura negra brasileira e o negro na formação da sociedade nacional, com as seguintes denominações, adequadas aos conteúdos relacionados ao Atletismo: a) Conhecendo a África por meio do Atletismo; b) Discutindo as diferenças e Conhecendo os atletas afro-brasileiros, respectivamente; e c) Consolidação, socialização e avaliação das aprendizagens, voltada para a síntese do curso.

O curso foi elaborado para atender a um número máximo de 20 pessoas com a intenção de se garantir maior interação e acompanhamento dos participantes, principalmente tendo em vista que a tutoria do curso foi feita, exclusivamente, pelo pesquisador. Borba, Malheiros e Amaral (2011), ao desenvolverem um curso de formação continuada de professores de Matemática, estabeleceram número semelhante (25) para que todos os alunos pudessem ser ouvidos e ter voz, mesmo porque, conforme estes mesmos autores, uma boa interação via internet compensa a ausência física do professor por meio de "[...] uma comunicação intensa, que limita a possibilidade do aluno se sentir sozinho, isolado" (BORBA; MALHEIROS; AMARAL, 2011, p. 28).

O curso foi cadastrado na Pró-Reitoria de Extensão da Universidade Estadual Paulista (Unesp) como um Curso de Difusão do Conhecimento e foi disponibilizado na Plataforma Moodle do ambiente virtual de aprendizagem da própria instituição, ficando, então, alocado no seguinte endereço: http://moodle.unesp.br/ava/course/view.php?id=674. Apresenta-se, na Figura 1, uma visão parcial do curso, destacando-se sua organização em tópicos semanais, um dos formatos possibilitados pela Plataforma Moodle. 
Figura 1 - Aparência parcial do curso

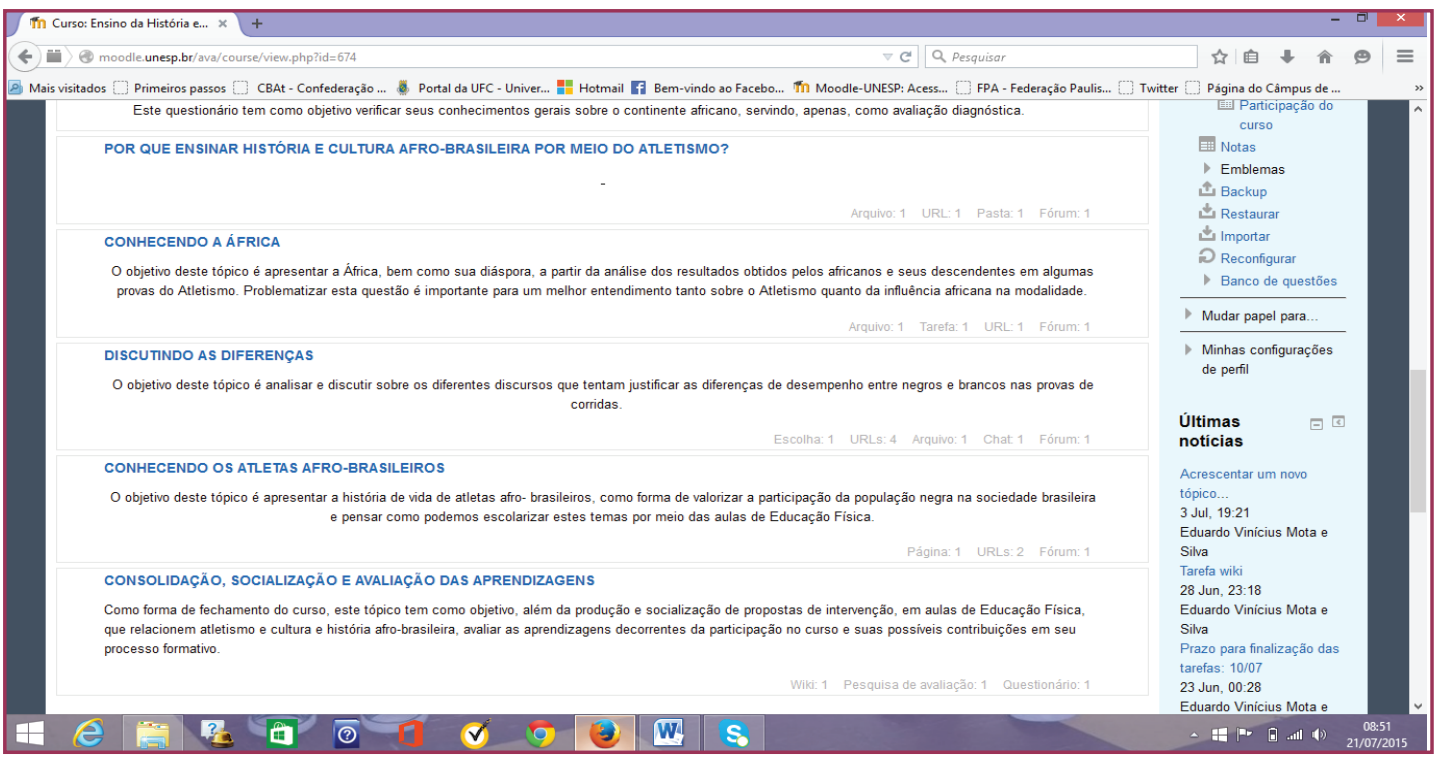

Fonte: Elaborado pelo autor (2016)

\subsection{A avaliação do curso}

Para que se pudessem verificar as contribuições do curso para o ensino da História e Cultura Afro-Brasileira por meio do Atletismo nas aulas de Educação Física na Educação Básica, foi disponibilizado, na própria Plataforma Moodle, um questionário aberto de autoria dos pesquisadores acerca da utilidade do Atletismo como ferramenta para o ensino da História e Cultura Afro-Brasileira, além de espaço para a livre manifestação dos participantes. Foram, ainda, consideradas as manifestações dos cursistas nos diversos fóruns realizados. Triviños (2013, p. 138) elenca o questionário aberto, juntamente com a Análise de Conteúdo e outros instrumentos, possivelmente como os "[...] mais decisivos para estudar os processos e produtos nos quais está interessado o investigador qualitativo".

\subsection{Análise dos dados}

Tanto para a análise das respostas do questionário quanto para perguntas formuladas por meio dos fóruns disponibilizados aos cursistas foi utilizada a Análise de Conteúdo, proposta por Bardin (2009, p. 31). Mesmo porque, conforme compreende essa autora, essa técnica é "[...] aplicável [...] a todas as formas de comunicação", permitindo que se alie a busca dos significados "[...] além das aparências [...]" à busca por rigor na interpretação das mensagens.

Campos (2004, p. 613), utilizando a Análise de Conteúdo, menciona a existência das seguintes fases: "[...] pré-exploração do material ou de leituras flutuantes [...], seleção das unidades de análise, [...] processo de categorização e subcategorização". Este, aliás, foi o procedimento utilizado no presente estudo. Ou seja, inicialmente, foram realizadas "[...] leituras flutuantes de todo o material com o intuito de apreender e organizar de forma não estruturada aspectos importantes para as próximas fases da análise" (CAMPOS, 2004, p. 613). Posteriormente, procedeu-se à análise temática, aquela que se utiliza do tema como unidade de registro. De acordo com Campos (2004, p. 613): "[...] o tema pode ser compreendido como uma escolha própria do pesquisador, vislumbrada através dos objetivos de sua pesquisa e indícios levantados do seu contato com o material estudado e teorias embasadoras [...]". 
A etapa seguinte consistiu na organização dos dados obtidos em categorias, definidas por Bardin (2009) como classes nas quais se agrupam elementos comuns em razão de suas características. Para a construção das subcategorias utilizou-se a recorrência das unidades de registro, a exemplo do efetuado por Barros (2013) em sua tese, ou seja, foram destacados os temas mais frequentemente citados pelos cursistas.

O presente método de pesquisa foi aprovado pelo Comitê de Ética e Pesquisa do Instituto de Biociências da Unesp - Rio Claro, de acordo com o parecer 908.510, em dezembro de 2014.

\section{RESULTADOS}

\subsection{Perfil dos participantes}

Dos vinte cursistas inscritos, dois não autorizaram a utilização de seus dados na pesquisa. Dos dezoito restantes, cinco (27,7\%) sequer acessaram a plataforma em que o curso foi desenvolvido, para a efetivação de seu cadastro no curso. Credita-se esse fenômeno à facilidade de inscrição no curso, via preenchimento de formulário online (Google docs), e à sua gratuidade, o que pode ter contribuído para que algumas pessoas se inscrevessem por impulso, sem maiores compromissos com sua realização.

No Quadro 2 são apresentados, então, os perfis dos treze participantes efetivos do curso de extensão que autorizaram a utilização de seus dados. Essas informações foram baseadas nos dados disponibilizados pelos participantes na ficha de inscrição do curso e nas mensagens do fórum de apresentações pessoais. Para garantir 0 anonimato dos participantes seus nomes reais foram substituídos por outros fictícios.

Quadro 1- Perfil dos participantes do curso

\begin{tabular}{|c|c|c|c|c|}
\hline Nome & Formação & Atuação & Motivo & $\begin{array}{l}\text { Completou } \\
\text { o curso? }\end{array}$ \\
\hline Talita & Licenciada & Professora Educação Básica & $\begin{array}{l}\text { Aquisição de conhecimentos } \\
\text { Interesse pelo tema }\end{array}$ & Sim \\
\hline Felipe & Licenciado & Professor ONG & $\begin{array}{l}\text { Interesse pelo tema } \\
\text { Conteúdo a ser ensinado }\end{array}$ & $30 \%$ \\
\hline Mariana & Licenciada & $\begin{array}{l}\text { Professora Educação Básica } \\
\text { Técnica de Atletismo }\end{array}$ & $\begin{array}{l}\text { Atualização profissional } \\
\text { Certificação } \\
\text { Rede de contatos }\end{array}$ & Sim \\
\hline Laura & Estudante & & $\begin{array}{l}\text { Aprender mais sobre o Atletismo e sua } \\
\text { história }\end{array}$ & $20 \%$ \\
\hline Diogo & $\begin{array}{l}\text { Licenciado } \\
\text { Especialista }\end{array}$ & $\begin{array}{l}\text { Coordenador } \\
\text { Técnico de Atletismo }\end{array}$ & Atualização profissional & $50 \%$ \\
\hline Alícia & $\begin{array}{l}\text { Licenciada } \\
\text { Mestre }\end{array}$ & $\begin{array}{l}\text { Professora Educação Básica } \\
\text { Doutoranda }\end{array}$ & Interesse pelo tema & $50 \%$ \\
\hline Júlia & Licenciada & & Aprender mais sobre o Atletismo & Sim \\
\hline Rodrigo & Estudante & & $\begin{array}{l}\text { Interesse pelo tema } \\
\text { Divulgação da temática afro-brasileira }\end{array}$ & $60 \%$ \\
\hline Eduardo & Licenciado & Técnico de Atletismo & $\begin{array}{l}\text { Interesse pela cultura afro-brasileira. } \\
\text { Conteúdo a ser ensinado }\end{array}$ & Sim \\
\hline Patrícia & $\begin{array}{l}\text { Licenciada } \\
\text { Mestre }\end{array}$ & $\begin{array}{l}\text { Coordenadora } \\
\text { Professora Educação Básica } \\
\text { Mestre }\end{array}$ & $\begin{array}{l}\text { Interesse pela Lei10.639/3. } \\
\text { Já desenvolve trabalho com esta temática }\end{array}$ & Sim \\
\hline
\end{tabular}


Continuação do quadro $1 .$.

\begin{tabular}{|c|c|c|c|c|}
\hline Irene & $\begin{array}{l}\text { Licenciada } \\
\text { Mestre }\end{array}$ & $\begin{array}{l}\text { Professora Educação Básica } \\
\text { Doutoranda }\end{array}$ & $\begin{array}{l}\text { Interesse pelo tema } \\
\text { Formação continuada } \\
\text { Aplicação em sala de aula } \\
\text { Conhecimento do Atletismo e da cultura } \\
\text { negra }\end{array}$ & Sim \\
\hline Amanda & Licenciada & $\begin{array}{l}\text { Professora Educação Básica } \\
\text { Mestre }\end{array}$ & Ensinar em sala de aula & Não \\
\hline Dalila & Licenciada & Mestranda & Interesse pelo tema & Sim \\
\hline
\end{tabular}

Fonte: Elaborado pelo autor (2015)

Conforme pode ser verificado no Quadro 2, apenas oito (44,5\%) cursistas concluíram o curso. Este índice foi bastante próximo ao atingido (50\%) por curso de EAD, sobre a mesma temática, analisado por Barros (2013) em sua tese de doutorado, quando este foi realizado exclusivamente a distância.

Dentre os concluintes do curso, todos eram licenciados, o que demonstra que, embora a intenção tenha sido a de oferecer um curso que pudesse ser acessado também por estudantes, este atendeu mais aos professores formados. Aliás, há que se destacar que 0 índice de aproveitamento do curso, entre eles, foi de $80 \%$. Consideraram-se como concluintes aqueles que realizaram, ao menos, $70 \%$ das tarefas exigidas. Entre os inscritos destacou-se o fato de que cinco $(27,8 \%)$ deles cursavam ou haviam cursado pós-graduação stricto sensu. Destes, três concluíram o curso.

\subsection{Atletismo como conteúdo para o ensino da história e cultura afro-brasileira em aulas de Educação Física}

Quando questionados sobre a adequação da utilização do Atletismo como conteúdo para o ensino da História e Cultura Afro-Brasileira em aulas de Educação Física, em um dos fóruns iniciais do curso, onze dos participantes apresentaram suas justificativas. Destaque-se que esta foi a atividade com maior participação e interação dos cursistas, talvez, por ter sido a mais específica em relação ao tema do curso.

Entre eles, foi unânime o entendimento de que o Atletismo é sim um conteúdo que possibilita o tratamento da História e Cultura Afro-Brasileira. Necessário ressaltar que o fórum foi realizado após a leitura de um texto elaborado especialmente para o curso, intitulado "Por que ensinar História e Cultura Afro-Brasileira por meio do Atletismo?", em que se apontavam alguns motivos pelos quais esta modalidade seria adequada a este ensino. Apesar disso, apenas uma aluna, Patrícia, afirmou ter modificado sua opinião em virtude da leitura do texto. Em suas palavras: "Acredito que sim! Agora que vi o curso. Mas nunca havia pensado nesta possibilidade. Sempre visualizei este ensino, no conteúdo de atividades rítmicas e expressivas, em lutas e em jogos e brincadeiras".

O principal motivo, apontado por sete dos participantes, que justificaria esta adequação seria o destaque alcançado pelos negros nas diversas provas do Atletismo, o que geraria a oportunidade de se estudar desde como se deu a inserção desta população na modalidade até os motivos para a sua prevalência em determinadas provas. Bastante reveladora destas possibilidades foi a afirmação, mais uma vez, da aluna Patrícia, que demonstra uma visão 
bastante recorrente nos diversos discursos que buscam explicações para a alta incidência de negros no Atletismo:

Quando trago para a aula a prevalência de pessoas negras inseridas no Atletismo e em outros esportes. Tento refletir e mostrar... como se deu a inserção inicial de pessoas negras no nosso país... Como a ocupação e profissão da maioria dos negros no Brasil foi e ainda são formas de trabalho braçais, estas pessoas e seus descendentes têm a tendência em serem mais fortes e resistentes, contribuindo para um bom desempenho esportivo... E quando voltamos o nosso olhar para o Atletismo, tem várias características do esporte que corroboram ou favorecem na participação dos negros brasileiros. Como, por exemplo, a maioria de pessoas pobres e de baixa renda no Brasil são negros. O Atletismo é um esporte que demanda poucos ou quase nenhum material/equipamentos para os treinamentos. Há projetos sociais, que eles podem se inserir [...].

A respeito dessa compreensão é importante destacar que há, realmente, no caso brasileiro, uma grande ligação entre o Atletismo ea população menos favorecida economicamente e negra, conforme apontado por Farias (2012, p. 28), para a qual esta modalidade é "[...] majoritariamente praticada por afro-brasileiros, pertencentes às camadas populares [...]", o que, em contrapartida, fez com que lhe fosse conferido "[...] um valor de inferioridade em relação ao status superior de outras modalidades esportivas, como esgrima, hipismo, tênis e natação, por exemplo". Essa marginalização pôde ser atestada pelas experiências sofridas por atletas negros do Atletismo no período da Ditadura Militar brasileira (FARIAS, 2012).

O segundo motivo, apontado por três dos estudantes, foi a possibilidade de se refletir sobre o processo de luta dos negros para a sua inserção na modalidade e, também, na sociedade de forma geral. Inclusive, o aluno Eduardo, em sua intervenção, utilizou como exemplo o protesto feito por atletas negros norte-americanos nos Jogos Olímpicos de 1968, realizados na Cidade do México, quando "[...] fizeram o símbolo dos Black Panthers ao subirem no pódio dos 200 metros rasos e foram banidos da competição pelo COI em uma época em que os negros estadunidenses lutavam por direitos civis". Essa, aliás, foi uma das poucas passagens do fórum em que houve a intervenção de outro cursista que afirmou desconhecer essa história e achar muito interessante tratar desse assunto com alunos adolescentes, por exemplo.

A posição desses alunos vai completamente ao encontro das determinações das DCN das Relações Étnico-Raciais que destacam a necessidade de que se divulgue e estude a "[...] participação dos africanos e de seus descendentes na diáspora, em episódios da história mundial" (BRASIL, 2004, p. 22).

Mereceram destaque, ainda, na opinião dos cursistas, o fato de a modalidade, em si, reproduzir a diversidade étnica brasileira e ser, possivelmente, um local em que a cultura negra é apresentada/difundida. Vieira e Freitas (2007, p. 23) reforçam essa percepção e creditam essa diversidade à simplicidade da maior parte das suas provas que acabam "[...] reunindo gente de todo tipo, abrindo possibilidades de glória para quem, muitas vezes, contava com pouco ou nenhum recurso".

Ao serem questionados, novamente, ao final do curso, sobre este assunto, no questionário de avaliação, foram inferidas de suas opiniões as categorias e subcategorias apresentadas no Quadro 2. 
Quadro 2 - Categoria e subcategorias referentes à adequação do Atletismo para o ensino da História e Cultura Afro-Brasileira

CATEGORIA 3 - Atletismo para o ensino da HCAB

- Adequado

- Sucesso dos negros na modalidade e sua relação com a inserção do negro na sociedade

- Histórico de luta contra a discriminação e o preconceito

- Expoentes negros

- Relações com a África

- Reprodução da diversidade étnica brasileira

- Não exclusivo

Espaço de afirmação da cultura negra

- Possibilidade inovadora

- Aplicável

Fonte: Dados da pesquisa (2016)

Novamente, os participantes foram unânimes em relatar que essa modalidade esportiva representa uma boa possibilidade para o tratamento da História e Cultura Afro-Brasileira. Alguns deles, inclusive, destacaram que o curso possibilitou essa compreensão. Dalila, por exemplo, fez o seguinte depoimento:

[...] me surpreendeu um pouco, pois quando falamos da cultura negra na escola pensamos imediatamente na capoeira e, isto pode ser visto também nos artigos científicos, então, nunca tinha pensado sob a ótica de utilizar este tema para a questão afro na escola.

Essa situação de proporcionar um novo olhar sobre a temática também foi mencionada por outros participantes. Irene, em sua fala, destaca que o Atletismo, enquanto conteúdo, possibilita a discussão da participação da população negra, não só na própria modalidade, como permite que esta seja transposta para a sua realidade na sociedade de forma geral.

As principais justificativas apontadas pelos participantes para a pertinência de utilização do Atletismo para a discussão da História e Cultura Afro-Brasileira foram, principalmente, o sucesso dos atletas negros nas provas de corridas e as diferentes justificativas utilizadas para explicar esta situação; a existência de atletas afro-brasileiros de destaque na modalidade; os casos de preconceito e discriminação existentes em sua história, bem como as de superação de tal situação. No decorrer do curso foram apresentadas, ainda, as seguintes justificativas: é uma modalidade que reproduz a diversidade étnica brasileira e é um espaço de afirmação da cultura negra.

Em relação à primeira justificativa, a aluna Dalila entende que o principal motivo para se utilizar o Atletismo para se discutir a temática é justamente a necessidade de se questionar os estereótipos que podem daí advir, como, por exemplo, a compreensão de que há uma aptidão natural dos negros para este tipo de atividades e não para outras. Maranhão (2016) destaca que a perspectiva de se atribuir essas habilidades à natureza ou a aspectos inatos pode contribuir para sua desumanização. Neste sentido, conforme destaca Canen (2007, p. 105), é importante, em propostas multiculturais de ensino, "[...] desafiar verdades únicas e posturas que homogeneízam as identidades e congelam as diferenças", justamente o que se procurou evidenciar no desenvolvimento do curso.

Outro destaque, bastante interessante, realizado pela aluna Irene é o de que o Atletismo apresenta grandes possibilidades para o tratamento da temática, mas ele não pode ser o único conteúdo utilizado para este fim; preocupação esta que expusemos durante o curso, em várias intervenções. 
Também merece destaque e reflexão a afirmação da cursista Patrícia de que, talvez, tratar a temática afro-brasileira por meio de uma manifestação, que, a princípio, não tem esta origem, facilite a sua aceitação por parte da direção escolar. Apesar de ser possível essa assertiva e bastante compreensível o entendimento da participante do curso, considera-se que esse não seja o caminho ideal, pois contraria a necessidade de que os currículos "[...] valorizem igualmente as diferentes e diversificadas raízes das identidades dos distintos grupos que constituem o povo brasileiro" (SILVA, 2005, p. 157), reservando, neste caso, seu tratamento a ocasiões em que ela possa ser dissimulada.

\section{CONSIDERAÇÕES FINAIS}

A simples oportunidade de se oferecer um curso de extensão que relacionasse a Educação Física à História e Cultura Afro-Brasileira, mesmo que a um público restrito, foi bastante enriquecedora, por, de certa forma, demonstrar que a aplicação dessa temática é importante, necessária e viável.

Com certeza, a oferta deste curso reflete a oportunidade aberta pela promulgação da Lei $n^{\circ}$ 10.639/03 que, aliás, deveria ser aproveitada por todos os componentes curriculares a fim de que contribua para a fundamental valorização do papel da população negra no desenvolvimento do Brasil. Para isto, as mais diversas possibilidades devem ser utilizadas, dentre as quais as trazidas pelas Tecnologias da Informação e Comunicação que, neste sentido, representam uma das grandes oportunidades para o tratamento desta temática.

De acordo com a opinião dos cursistas foi possível perceber que houve contribuições do curso tanto para o ensino da História e Cultura Afro-Brasileira nas aulas de Educação Física na Educação Básica, por apresentar uma possibilidade inovadora, ao se associar o tratamento da temática ao Atletismo e apresentar possibilidades concretas de intervenção, quanto para a formação continuada de professores de Educação Física, não só no aspecto técnico, mas, também, em relação à sua formação pessoal e como cidadãos.

Especificamente em relação ao Atletismo, conteúdo clássico da Educação Física, e à possibilidade de sua utilização como ferramenta para o ensino da História e Cultura AfroBrasileira, foi possível perceber que há, realmente, uma grande potencialidade para a sua utilização com esta finalidade, visto que a grande presença de africanos e seus descendentes nas provas atléticas, bem como o impacto de sua presença e a sua contemporânea prevalência em provas de corrida podem ser adequadamente problematizadas para a compreensão e valorização de sua presença, além da reflexão sobre os estereótipos, muitas vezes, a eles atribuídos. No caso específico do Atletismo brasileiro ficou patente que, apesar da pequena quantidade de publicações que possam servir de base para a sua correta utilização com este intuito, há uma interessante e crescente produção videográfica que, potencialmente, pode ser utilizada como deflagradora de importantes reflexões sobre a importância de grandes atletas negros como Adhemar Ferreira da Silva, Nélson Prudêncio e Aída dos Santos, bem como de suas histórias de vida, para a compreensão das contribuições e consequente valorização do papel desta população na sociedade brasileira. 


\section{REFERÊNCIAS}

BARDIN, Laurence. Análise de conteúdo. Lisboa: Edições 70, 2009.

BARROS, Zelinda Santos. Implicações da formação a distância para o ensino de história e cultura afro-brasileiras. 2013. 230 f.. Tese (Doutorado em Estudos Étnicos e Africanos) Faculdade de Filosofia e Ciências Humanas, Centro de Educação, Universidade Federal da Bahia, Salvador, 2013.

BORBA, Marcelo de Carvalho; MALHEIROS, Ana Paula dos Santos; AMARAL, Rúbia Barcelos. Educação a distância online.3. ed. Belo Horizonte: Autêntica, 2011.

BRACHT, Valter. A Educação Física no ensino fundamental. In: SEMINÁRIO NACIONAL DO CURRÍCULO EM MOVIMENTO, 1., 2010, Belo Horizonte. Anais... Brasília: Ministério da Educação. Secretaria de Educação Básica, 2010. Disponível em: <http://portal.mec.gov.br/index. php?option=com docman\&task=doc download\&gid=7170\&ltemid=>. Acesso em: 5 fev. 2018.

BRASIL. Lei no $\mathbf{1 1 . 6 4 5 / 0 8}$, de 10 de março de 2008. Altera a Lei no $\mathbf{9 . 3 9 4}$, de 20 de dezembro de 1996, modificada pela Lei $\mathrm{n}^{\circ} \mathbf{1 0 . 6 3 9}$, de 9 de janeiro de 2003, que estabelece as diretrizes e bases da educação nacional, para incluir no currículo oficial da rede de ensino a obrigatoriedade da temática "História e Cultura Afro-Brasileira e Indígena". Disponível em: <http://www.planalto. gov.br/ccivil 03/ ato2007-2010/2008/lei/l11645.htm>. Acesso em 5 fev. 2018.

BRASIL. Ministério da Educação e do Desporto. Secretaria de Educação Fundamental. Parâmetros curriculares nacionais: Educação Física. Brasília: MEC/SEF, 1998. Disponível em: < http://portal.mec.gov.br/seb/arquivos/pdf/fisica.pdf>. Acesso em: 5 fev. 2018.

BRASIL. Ministério da Educação. Secretaria Especial de Políticas de Promoção da Igualdade Racial. Diretrizes Curriculares Nacionais para a Educação das Relações Étnico-Raciais e para o Ensino de História e Cultura Afro-Brasileira e Africana. Brasília: Ministério da Educação, Secretaria Especial de Políticas de Promoção da Igualdade Racial, 2004. Disponível em: <http://www.relacoesraciaisnaescola.org.br/site/pdfs/Legislacao Link 3 Diretrizes.pdf>. Acesso em: 5 fev. 2018.

CAMPOS, Claudinei José Gomes. Método de análise de conteúdo: ferramenta para a análise de dados qualitativos no campo da saúde. Revista Brasileira de Enfermagem, v. 57, n.5, p. 611614, set./out. 2004.

CANEN, Ana. O multiculturalismo e seus dilemas: implicações na educação. Comunicação e política, v. 25, n.2, p.91-107, 2007.

CANEN, Ana; OLIVEIRA, Ângela Maria de Almeida. Multiculturalismo e currículo em ação: um estudo de caso. Revista Brasileira de Educação, n. 21, p. 61-74, set./ dez. 2002.

CAVALCANTE, Ricardo Bezerra; CALIXTO, Pedro; PINHEIRO, Marta Macedo Kerr. Análise de conteúdo: considerações gerais, relações com a pergunta de pesquisa, possibilidades e limitações do método. Informação e Sociedade: estudos, v.24, n. 1, p. 13-18, jan./abr. 2014.

DARIDO, Suraya Cristina et al. Educação física e temas transversais: possibilidades de aplicação. São Paulo: Mackenzie, 2006.

FARIAS, Claudia Maria. $O$ atletismo feminino brasileiro sob a ditadura civil-militar: novos obstáculos e caminhos. La manzana de la discordia, v.7, n. 1, p. 23-40, jan. 2012. 
GALVÃO, Zenaide; RODRIGUES, Luiz Henrique; SANCHES NETO, Luiz. Cultura corporal de movimento. In: DARIDO, Suraya Cristina; RANGEL, Irene Conceição Andrade. Educação Física na escola: implicações para a prática pedagógica, 2. ed. Rio de Janeiro: Guanabara Koogan, 2011. p. 25-36.

GONÇALVES JUNIOR, Luiz. Dialogando sobre a capoeira: possibilidades de intervenção a partir da Motricidade Humana. Motriz, v.15, n. 3, p. 700-707, jul./set. 2009.

LÜDKE, Menga; ANDRÉ, Marli Eliza Dalmazo Afonso. Pesquisa em educação: abordagens qualitativas. São Paulo: EPU, 1986.

MARANHÃO, Fabiano. Relações étnico-raciais no contexto da Educação física brasileira. In: CORSINO, Luciano Nascimento; CONCEIÇÃO, Willian Lazareti (orgs.). Educação física escolar e relações étnico-raciais: subsídios para a implementação das leis 10.639/03 e 11.645/08. Curitiba: CRV, 2016. p. 59-70.

MARCONI, Marina de Andrade; LAKATOS, Eva Maria. Técnicas de pesquisa. 7. ed. 7. reimpr. São Paulo: Atlas, 2013.

MATTHIESEN, Sara Quenzer. Atletismo: teoria e prática. Rio de Janeiro: Guanabara Koogan, 2007.

MATTOS, Ivanilde Guedes. A negação do corpo negro: representações sobre o corpo no ensino da educação física. 2007. 148 f.. Dissertação (Mestrado em Educação e Contemporaneidade) Universidade do Estado da Bahia, Salvador, 2007.

MENDES, Conrado Moreira. A pesquisa online: potencialidades da pesquisa qualitativa no ambiente virtual. Hipertextus: revista digital, n. 2, jan. 2009. Disponível em: <http://www. hipertextus.net/volume2/Conrado-Moreira-MENDES.pdf>. Acesso em: 5 fev. 2018.

OLIVEIRA, Altemir. A participação do atleta negro no esporte: das pistas de atletismo às pistas de Fórmula 1. Lecturas, Educación Física y Deportes: revista digital, Buenos Aires, ano 13, n. 126, nov. 2008. Disponível em: <http://www.efdeportes.com/efd126/a-participacao-do-atleta-negrono-esporte.htm>. Acesso em: 5 fev. 2018.

ORO, Ubirajara. Prefácio. In: SIMONI, Clarissa Rios; TEIXEIRA, William Medeiros. Atletismo em quadrinhos: história, regras, técnicas e glossário. Porto Alegre: Rígel, 2009. p. 13-19.

PIRES, Joice Vigil Lopes; SOUZA, Maristela da Silva. Educação física e a aplicação da Lei no 10.639/03: análise da legalidade do ensino da cultura afro-brasileira e africana em uma escola municipal do RS. Movimento, v. 21, n. 1, p. 193-204, jan./mar. 2015.

RANGEL, Irene Conceição Andrade. Racismo, preconceito e exclusão: um olhar a partir da Educação Física Escolar. Motriz, v.12, n. 1, p. 73-76, jan./abr., 2006.

RANGEL, Irene Conceição Andrade et al. Educação Física Escolar e multiculturalismo: possibilidades pedagógicas. Motriz, v.14 n.2, p.156-167, abr.jun. 2008.

RODRIGUES, Antônio Cesar Lins. Corpos e culturas inviabilizados na escola: racismo, aulas de Educação Física e insurgência multicultural. 2013. 237 f.. Tese (Doutorado em Educação) Faculdade de Educação, Universidade de São Paulo, São Paulo, 2013.

RODRIGUES, Luiz Henrique; GALVÃO, Zenaide. Novas formas de organização dos conteúdos. In: DARIDO, Suraya Cristina; RANGEL, Irene Conceição Andrade. Educação Física na escola: 
implicações para a prática pedagógica. 2. ed. Rio de Janeiro: Guanabara Koogan, 2011. p. 80102.

SANTOS, Marzo Vargas. 0 estudante negro na cultura estudantil e na educação física escolar. 2007. 240 f.. Dissertação (Mestrado em Ciências do Movimento Humano) - Escola de Educação Física, Universidade Federal do Rio Grande do Sul, Porto Alegre, 2007.

SILVA, Petronília Beatriz Gonçalves. Aprendizagem e ensino das africanidades brasileiras. In: MUNANGA, K. (org.). Superando o racismo na escola. 2. ed. Brasília: Ministério da Educação, Secretaria de Educação Continuada, Alfabetização e Diversidade, 2005. p. 155-172.

SOARES, Dandara Carvalho. A temática afro-brasileira no contexto da Educação Física escolar. 2015. 60 f. Trabalho de conclusão de curso (Licenciatura em Educação Física) - Instituto de Biociências, UNESP, Rio Claro, 2015.

TRIVIÑOS, Augusto Nivaldo Silva. Introdução à pesquisa em ciências sociais: a pesquisa qualitativa em educação. 1. ed. 22. reimpr. São Paulo: Atlas, 2013.

TUBINO, Manoel José Gomes. Estudos brasileiros sobre o esporte: ênfase no esporteeducação. Maringá : Eduem, 2010.

VIEIRA, Silvia; FREITAS, Armando. O que é Atletismo? Rio de Janeiro: Casa da Palavra: COB, 2007. 
